\title{
Prevalence and Associated Factors with Maternal Near-Miss among Pregnant Women at Hawassa University Comprehensive Specialized Hospital, Sidama Region, Ethiopia
}

\author{
Dereje Tolesa ${ }^{1}$, Netsanet Abera ${ }^{2}$, Misganew Worku' ${ }^{2}$ and Biresaw Wassihun ${ }^{1^{*}}$ \\ ${ }^{1}$ College of Medicine and Health Science, Arba Minch University, Arba Minch, Ethiopia \\ ${ }^{2}$ College of Medicine and Health Science, Hawassa University, Hawassa, Ethiopia
}

*Corresponding author: Biresaw Wassihun, College of Medicine and Health Science, Arba Minch University, Arba Minch, Ethiopia

\begin{abstract}
Background: Maternal near miss refers to a very ill pregnant or delivered woman who nearly died but survived a complication during pregnancy, childbirth, or within 42 days of termination of pregnancy. It is an important public health problem in developing country including Ethiopia.

Objective: To assess the prevalence and associated factors with maternal near-miss among pregnant women at Hawassa university's comprehensive specialized hospital, 2020.

Method: Health facility-based cross-sectional study was done from May to June 2020. Structured questionnaires were used to collect the data from 316 study participants. The data were entered with Epi data version 4.4 and exported to Statistical Package for Social Sciences (SPSS) version 25.0 for analysis. Binary logistic regression was done. Statistical significance was declared at P-values < 0.05 with a $95 \% \mathrm{Cl}$.

Result: The finding of this study revealed that the prevalence of maternal near-miss was $16.1 \%$ with $95 \% \mathrm{Cl}(12.3,20.3)$. Almost half of the underlying cause of maternal near-miss was a hypertensive disorder of pregnancy and nearly $75 \%$ of maternal near-miss occurred before arrival to a health facility. Variables such as rural residence [AOR: $4.2,95 \% \mathrm{Cl}$ $(1.3,13.9)]$, referred women [AOR: $5.5,95 \% \mathrm{Cl}(1.8,17.4)]$, previous history of stillbirth [AOR: $10.2,95 \% \mathrm{Cl}(1.4,71.8)]$ and time takes to reach hospital [AOR: $4.8,95 \% \mathrm{Cl}(1.34$, 16.9)] were found to be associated factors with maternal near-miss.
\end{abstract}

Conclusion: In this study, the prevalence of maternal nearmiss was relatively high. Being a rural residence, referred women, the time takes to reach the hospital, and the previous stillbirth were the factors independently associated with the occurrence of maternal near-miss. The presence of maternal near-miss in women is an independent risk factor for adverse perinatal outcomes. Strengthening the available health system in rural parts of the country with a focus on maternity service is also a crucial step to avert serious maternal complications. Hence, interventions rendered at the improvement in maternal health can lead to an improvement in perinatal outcomes.

\section{Keywords}

Prevalence, Maternal near-miss, Hawassa

\section{List of Abbreviations}

AOR: Adjusted Odds Ratio; ANC: Antenatal Care; SSA: Sub Saharan Africa; WHO: World Health Organization

\section{Background}

Maternal death is the most catastrophic end that could happen to a pregnant woman. It is frequently described as just the "tip of the iceberg" while maternal morbidity is the "base," and for every woman who dies, many more will survive but often suffer from lifelong disabilities [1,2].

World Health Organization (WHO) defines the maternal near-miss event as "a woman who nearly died but survived a complication that occurred during pregnancy, childbirth or within 42 days of termination of pregnancy" $[3,4]$.

Citation: Tolesa D, Abera N, Worku M, Wassihun B (2021) Prevalence and Associated Factors with Maternal Near-Miss among Pregnant Women at Hawassa University Comprehensive Specialized Hospital, Sidama Region, Ethiopia. Int J Womens Health Wellness 7:127. doi.org/10.23937/24741353/1510127

Accepted: November 06, 2021: Published: November 08, 2021

Copyright: (C) 2021 Tolesa D, et al. This is an open-access article distributed under the terms of the Creative Commons Attribution License, which permits unrestricted use, distribution, and reproduction in any medium, provided the original author and source are credited. 
In September 2015, the United Nations (UN) General Assembly formally approved a set of 17 Sustainable Development Goals (SDG) as a follow-up to Millennium Development Goals (MDGs). Improving maternal health remains an important topic of SDG, which is to reduce the global Maternal Mortality Ratio (MMR) to less than 70 per 100,000 live births by $2030[5,6]$.

Globally, 303,000 maternal deaths occurred in 2015 with sub-Saharan Africa alone accounts for $66 \%$ of the deaths [6]. Maternal mortality continues to be of great public health importance because many more women experience life-threatening complications, during pregnancy, delivery, and postpartum complications. Despite all the efforts on maternal health care, maternal near-miss, disabilities, and deaths were exceptionally high in developing countries, including Ethiopia [7-9].

In Ethiopia, maternal near-miss complications are common and are estimated to be around 12 times more frequent than maternal deaths [10].

According to the Ethiopian Demographic and Health Survey (EDHS, 2016) report, MMR is 412 per 100,000 live births, and for every maternal death, $10 \%$ to $15 \%$ of the women develop disability from pregnancy and pregnancy-related complications. Ethiopia is one of five countries that account for half of the maternal deaths globally; about 20,000 women die each year from pregnancy and childbirth complications [11-13].

Review of kinds of literature around the world reported different factors for maternal near-miss which may be contributing to negative outcomes, like poor ANC follow up, maternal age, rural area, previous cesarean section, stillbirth history, family income, referred, maternal delay including late diagnosis, a late arrival to hospital and lack of materials [13-15]. Maternal nearmiss prevalence and factors are inconsistent throughout the world and in Ethiopia. Up-to-date information on the prevalence and factors of maternal near-miss is important to know areas of interventions that help to improve maternal and perinatal health.

Thus, the findings of the current study are vital to fill the knowledge gap, and it will provide reliable evidence for policymakers, programmers, and health practitioners. Therefore, the objective of this study was to assess the prevalence and associated factors with maternal near-miss among pregnant women at Hawassa university's comprehensive specialized hospital.

\section{Methods and Materials}

\section{Study area and period}

The study was conducted in Hawassa University Comprehensive Specialized Hospital from May 1 to June 30,2020 . Hawassa is the capital city of the Sidama region located $275 \mathrm{~km}$ south of Addis Ababa, the capital city of Ethiopia.

\section{Study design}

An institution-based cross-sectional study was conducted Source and Study Populations. Women who were admitted at selected hospitals during pregnancy, labor, or within the first 42 days of termination of pregnancy.

\section{Sample size determination}

The sample size was calculated using a single population proportion formula by considering the following assumptions: $95 \%$ confidence level, the margin of error (0.05), $p=24.8 \%$ (25) the required sample size after adding a $10 \%$ non-response rate was 316 .

\section{Sampling techniques \& procedure}

Individual study subject at was selected by systematic random sampling during the data collection period until the required sample size was obtained.

The sampling interval $\mathrm{k}=4$ was calculated by dividing the source population by the total sample size and this interval was used to select study subjects.

Therefore, the first women were selected by the lottery method. Then every $4^{\text {th }}$ woman was selected and interviewed.

\section{Data collection tool and quality control}

Before actual data collection occurred two-day training was provided for data collectors and the supervisor about techniques of data collection and briefed on each question. The pretest was done on 5\% of mothers receiving care in a health center that was not included in the study before the actual study period. After pre-testing the questionnaire, Cronbach's Alpha was calculated by using SPSS window version 25.0 to test the internal consistency (reliability) of the item, and Cronbach's Alpha greater than 0.7 was considered as reliable. Data were collected by trained midwives and nurses. During data collection, regular supervision was done by the supervisors.

\section{Data analysis and interpretation}

The collected data were checked manually for completion and any incomplete or misfiled questions, cleaned and stored for consistency, entered into EpiData version 4.4. (EpiData Association, Odense, Denmark), and then exported to SPSS version 25.0 (IBM Corp., Armonk, NY, USA) for analysis. Descriptive statistics were calculated and presented using tables and figures. Multivariable logistic regression analysis was performed to adjust for possible confounding variables. Variables that were significant in the bivariate logistic regression were entered into the multiple regression analysis. The $p<0.05$ or $95 \%$ confidence intervals (Cls) not including 1.0 were considered to indicate statistical significance. 


\section{Ethical approval and consent to participant}

Ethical clearance was obtained from the institutional Research Ethics review board of the college of medicine and health science, Hawassa University. Permission was obtained from the managers of the hospital. After the purpose and objective of the study have been informed, informed verbal consent was obtained from each study participant. Moreover, the confidentiality of information was guaranteed by using code numbers rather than personal identifiers and by keeping the data locked.

Table 1: Socio-demographic characteristics of the study participants, Hawassa university's comprehensive and specialized hospitals, Hawassa, Ethiopia, 2020, $(n=316)$.

\begin{tabular}{|c|c|c|}
\hline $\begin{array}{l}\text { Socio-demographic } \\
\text { characteristics }\end{array}$ & Category & Frequency (\%) \\
\hline \multirow[t]{6}{*}{ Age } & $15-20$ & $21(6.6 \%)$ \\
\hline & $21-24$ & $93(29.4 \%)$ \\
\hline & $25-30$ & $94(29.7 \%)$ \\
\hline & $31-34$ & $72(22.8 \%)$ \\
\hline & $35-40$ & $27(8.5 \%)$ \\
\hline & $>40$ & $9(2.8 \%)$ \\
\hline \multirow[t]{2}{*}{ Place of Residence } & Rural & $96(30.4 \%)$ \\
\hline & Urban & $220(69.6 \%)$ \\
\hline \multirow[t]{5}{*}{ Ethnicity } & Sidama & $146(46.2 \%)$ \\
\hline & Amhara & $47(14.9 \%)$ \\
\hline & Oromo & $107(33.9 \%)$ \\
\hline & Wolayta & $9(2.8 \%)$ \\
\hline & Others & $7(2.2 \%)$ \\
\hline \multirow{4}{*}{ Current marital status } & Single & $36(11.4 \%)$ \\
\hline & Married & $270(85.4 \%)$ \\
\hline & Divorced & $8(2.5 \%)$ \\
\hline & Widowed & $2(0.6 \%)$ \\
\hline \multirow[t]{4}{*}{ Education status } & $\begin{array}{l}\text { No formal } \\
\text { education }\end{array}$ & $26(8.2 \%)$ \\
\hline & Primary school & $135(42.7 \%)$ \\
\hline & Secondary & $82(25.9 \%)$ \\
\hline & $\begin{array}{l}\text { College and } \\
\text { above }\end{array}$ & $73(23.1 \%)$ \\
\hline \multirow[t]{6}{*}{ Occupation } & Farmer & $13(4.1 \%)$ \\
\hline & Merchant & $61(19.3 \%)$ \\
\hline & Government & $65(20.6 \%)$ \\
\hline & Housewife & $127(40.2 \%)$ \\
\hline & Daily laborer & $22(7.0 \%)$ \\
\hline & Others & $28(8.9 \%)$ \\
\hline \multirow[t]{4}{*}{ Religion } & Orthodox & $116(36.7)$ \\
\hline & Muslim & $86(27.2 \%)$ \\
\hline & Protestants & $111(35.1 \%)$ \\
\hline & others & $3(0.9 \%)$ \\
\hline \multirow[t]{3}{*}{ Monthly income } & $<2000$ & $82(26 \%)$ \\
\hline & $2000-4000$ & $117(37 \%)$ \\
\hline & $>4000$ & $117(37 \%)$ \\
\hline
\end{tabular}

\section{Results}

\section{Socio-demographic characteristics of respondents}

Three-hundred sixty women participated in the study with a $100 \%$ response rate. The mean age of the study participants was 26 years (SD \pm 5.6 years) and the majority, of the study participants, 270 (85.4\%) were married. Among the total respondents, 26 (8.2\%) of women had no formal education level and (36.7\%) were Orthodox Christians. Half of the respondents were from Sidama ethnic group (46.2\%). Two third of the respondent, 220 (69.6\%) were urban residents whereas 96 (30.4\%) were from rural residents. Of the respondents, 127 (40.2\%) were housewives and 65 (20.6\%) were government employed (Table 1 ).

\section{Obstetrics and gynecological characteristics of the respondents}

Of the total respondents nearly half of the study participants, 152 (48.1\%) were multi-gravid. The

Table 2: Obstetrics characteristics of the study participants, Hawassa university's comprehensive and specialized hospitals, Hawassa, Ethiopia, 2020, $(n=316)$.

\begin{tabular}{|c|c|c|}
\hline $\begin{array}{l}\text { Gynecological and } \\
\text { obstetrics related factors }\end{array}$ & Category & Frequency (\%) \\
\hline \multirow[t]{3}{*}{ Gravidity } & Gravida 1 & $134(42.4 \%)$ \\
\hline & Gravida 2-4 & $152(48.1 \%)$ \\
\hline & Gravida $>4$ & $30(9.5 \%)$ \\
\hline \multirow[t]{3}{*}{ Parity $(n=168)$} & para 1 & $91(54.2 \%)$ \\
\hline & para 2-4 & $64(38.1 \%)$ \\
\hline & Para $>4$ & $13(7.7 \%)$ \\
\hline \multirow[t]{2}{*}{ Current pregnancy } & Wanted & $283(89.6 \%)$ \\
\hline & Unwanted & $33(10.4 \%)$ \\
\hline \multirow[t]{2}{*}{ History of stillbirth } & Yes & $11(3.2 \%)$ \\
\hline & No & $305(96.8 \%)$ \\
\hline \multirow{2}{*}{$\begin{array}{l}\text { Number of stillbirths }(n= \\
11)\end{array}$} & Once & $8(72.7 \%)$ \\
\hline & $\begin{array}{l}\text { More than } \\
\text { once }\end{array}$ & $3(27.3 \%)$ \\
\hline \multirow[t]{2}{*}{ History of abortion } & Yes & $26(8.2 \%)$ \\
\hline & No & $290(91.8 \%)$ \\
\hline \multirow[t]{2}{*}{ ANC follow up } & Yes & $241(76.3)$ \\
\hline & No & $75(23.7 \%)$ \\
\hline \multirow[t]{2}{*}{ Referred case } & Yes & $72(22.8 \%)$ \\
\hline & No & $244(77.2 \%)$ \\
\hline \multirow[t]{3}{*}{ Source of referral $(n=72)$} & Health center & $22(30.6 \%)$ \\
\hline & Hospitals & $32(44.4 \%)$ \\
\hline & Private clinic & $18(25 \%)$ \\
\hline \multirow{2}{*}{$\begin{array}{l}\text { Previous history of CS } \\
\text { delivery }\end{array}$} & Yes & $19(6.0 \%)$ \\
\hline & No & $297(96.0 \%)$ \\
\hline \multirow[t]{2}{*}{ Type of pregnancy } & Singleton & $306(96.8 \%)$ \\
\hline & Multiply & $10(3.2 \%)$ \\
\hline \multirow{2}{*}{$\begin{array}{l}\text { Preexisting medical } \\
\text { condition }\end{array}$} & Yes & $20(6.3 \%)$ \\
\hline & No & $296(93.7 \%)$ \\
\hline
\end{tabular}


majority, 283 (98.6\%) pregnancies were wanted. Of all respondents, $11(3.2 \%)$ had a history of stillbirth and $26(8.2 \%)$ had a history of abortion. Regarding ANC follow up only three fourth 241 (76.3\%) of pregnant women had ANC follow-up. 72 (22.8\%) of the study participants were referred from another health facility. Of the respondents, 19 (6.0\%) had a previous history of CS. Concerning the type of pregnancy majority, 306 (96.8\%) of the participants were singleton. Among the respondents, $20(6.3 \%)$ had preexisting medical conditions and such as hypertension (25\%), Diabetes mellitus (20\%), and HIV (20\%) (Table 2).

\section{Prevalence and causes of maternal near-miss}

The prevalence of maternal near-miss was (16.1\%), with $95 \% \mathrm{Cl}(12.3,20.3)$ among women visited at Hawassa university's comprehensive specialized hospital. Of those. The intervention given for management of maternal near-miss was blood transfusion (19.6\%), laparotomy (13.7\%), $7 \mathrm{H}_{2} \mathrm{O} . \mathrm{MgSO}_{4}(41.2 \%)$ and antibiotics (25.5\%). The majority of maternal near-miss cases was hypertensive disorder 21 (41.2\%), followed by sepsis 12 (23.5\%), Obstetric hemorrhage 10 (19.6\%), OL/uterine rupture $5(9.8 \%)$, and pregnancy with abortive outcome 3 (5.9\%) (Figure 1).

\section{Three delays of reproductive health services}

Of the respondents, 12 (3.8\%) of pregnant women were delayed in seeking health care facilities. The dominant reason for the first delay was traditional practices $(41.7 \%)$ followed by underestimating severe conditions $(25 \%)$, belief that God was in control (16.7\%), lack decision to go to the hospital (8.3\%), and bad experience to health systems (8.3\%). Most of the study participants, $271(85.8 \%)$ were reached the hospital within 60 minutes to receive care. The median time taken to reach the final care health facility (second delay) among study participants was reportedly 40 minutes with an IQR of 20 minutes. Regarding the Third delay (delay in receiving care) the median time taken to get clinical interventions was 10 minutes after admission to the hospital. Of the respondents, 42 (13.3\%) faced problems in the hospital. Of the problems lack of supply and equipment's, 19 (45.2\%) were the most predominant problem for the third delay in the hospital (Table 3).

\section{Factors contributing to maternal near-miss}

In multivariable logistic regression analysis; place of residency, referred women, history of stillbirth, and time taken to reach this hospital were significantly

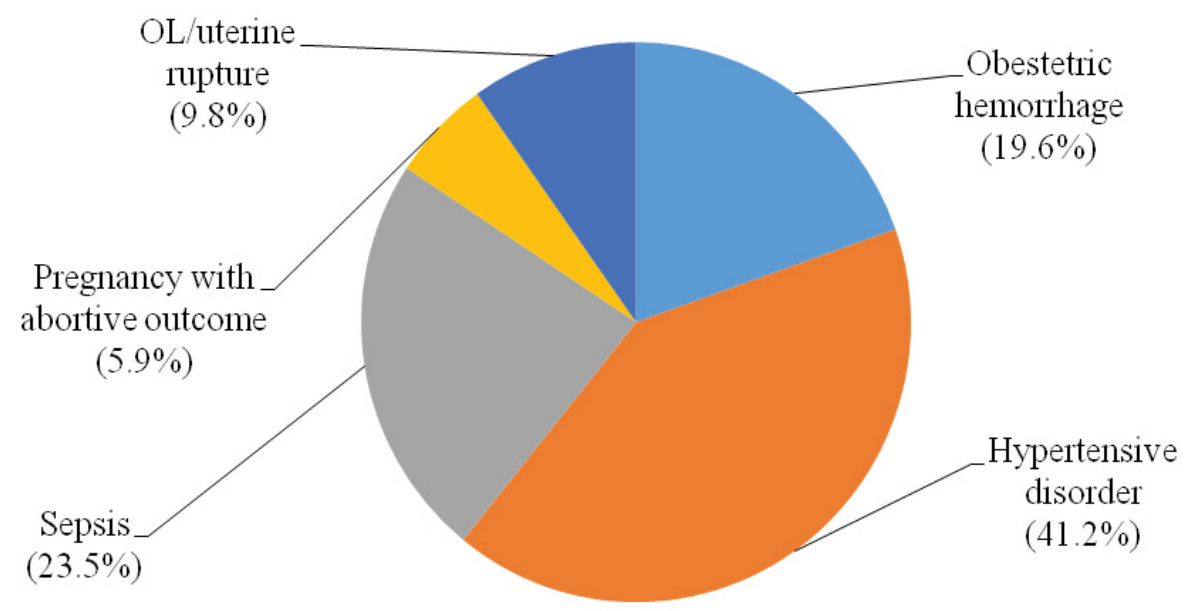

Figure 1: Underlying causes of maternal near-miss among women visited at Hawassa university comprehensive and specialized hospitals, Hawassa, Ethiopia, 2020.

Table 3: Three delays on access to reproductive health services among the study participants, Hawassa university's comprehensive and specialized hospitals, Hawassa, Ethiopia, 2020, $(n=316)$.

\begin{tabular}{|l|l|l|}
\hline Access to reproductive health services & Category & Frequency (\%) \\
\hline Delay in deciding to seek health facility & Yes & $12(3.8 \%)$ \\
\hline \multirow{2}{*}{ Time to reach the hospital } & No & $304(96.2 \%)$ \\
\hline Delay at treating hospital & Within 60 minute & $271(85.8 \%)$ \\
\cline { 2 - 3 } & $>60$ minute & $45(14.2 \%)$ \\
\hline Did you face problems in hospitals & $<=30$ minute & $292(92.8 \%)$ \\
\hline & $>30$ minute & $24(7.2 \%)$ \\
\hline & Yes & $42(13.3 \%)$ \\
\hline
\end{tabular}


Table 4: Bi-variable and multivariable binary logistic regression model on factors associated with maternal near-miss women visited at HUCSH, Hawassa, Ethiopia, 2020 ( $\mathrm{N}=316)$.

\begin{tabular}{|c|c|c|c|c|c|}
\hline \multirow[t]{2}{*}{ Variables } & \multirow[t]{2}{*}{ Category } & \multicolumn{2}{|c|}{ Near-miss } & \multirow[t]{2}{*}{ COR $(95 \% \mathrm{CI})$} & \multirow[t]{2}{*}{ AOR $(95 \% \mathrm{Cl})$} \\
\hline & & Yes & No & & \\
\hline \multirow[t]{2}{*}{ Place of residency } & Rural & 32 & 64 & $5.3(2.8,9.9)$ & $4.2(1.3,13.9)^{\star}$ \\
\hline & Urban & 19 & 201 & 1 & 1 \\
\hline \multirow{3}{*}{$\begin{array}{l}\text { Estimated monthly } \\
\text { income }\end{array}$} & $<2000$ & 19 & 63 & $2.4(1.1,5.2)$ & $0.72(0.14,3.7)$ \\
\hline & $2000-4000$ & 19 & 98 & $1.6(0.73,3.3)$ & $1.2(0.35,4.7)$ \\
\hline & $>4000$ & 13 & 104 & 1 & 1 \\
\hline \multirow[t]{2}{*}{ Educational status } & $\begin{array}{l}\text { No formal } \\
\text { education }\end{array}$ & 10 & 16 & $3.8(1.6,8.9)$ & $2.6(0.49,13.7)$ \\
\hline & $\begin{array}{l}\text { Have formal } \\
\text { education }\end{array}$ & 41 & 249 & 1 & 1 \\
\hline \multirow[t]{3}{*}{ Parity } & Para 1 & 10 & 81 & 1 & 1 \\
\hline & Para 2-4 & 13 & 51 & $2.1(0.84,5.1)$ & $1.2(0.32,4.6)$ \\
\hline & Para $>4$ & 5 & 8 & $5.1(1.4,18.5)$ & $0.22(0.02,3.1)$ \\
\hline \multirow[t]{2}{*}{ Gravidity } & Prim-gravid & 22 & 112 & $0.7(0.35,1.3)$ & $0.52(0.1,2.9)$ \\
\hline & Multi-gravid & 29 & 152 & 1 & 1 \\
\hline \multirow[t]{2}{*}{ Referral case } & Yes & 36 & 36 & $15(7.6,30.7)$ & $5.5(1.8,17.4)^{\star}$ \\
\hline & No & 15 & 229 & 1 & 1 \\
\hline \multirow[t]{2}{*}{ History of stillbirth } & Yes & 5 & 5 & $5.6(1.6,20)$ & $10.2(1.4,71.8)^{*}$ \\
\hline & No & 46 & 259 & 1 & 1 \\
\hline \multirow[t]{2}{*}{ History of abortion } & Yes & 2 & 24 & $0.41(0.1,1.8)$ & $0.2(0.01,3.9)$ \\
\hline & No & 49 & 241 & 1 & 1 \\
\hline \multirow{2}{*}{$\begin{array}{l}\text { Delay to make a } \\
\text { decision }\end{array}$} & Yes & 8 & 4 & $12.5(3.5,42)$ & $1.2(0.12,7.7)$ \\
\hline & No & 43 & 261 & 1 & 1 \\
\hline \multirow{2}{*}{$\begin{array}{l}\text { Time to reachthe } \\
\text { hospital }\end{array}$} & Within 60 minute & 28 & 243 & 1 & 1 \\
\hline & $>60$ minute & 23 & 22 & $9.1(4.5,18.3)$ & $4.8(1.34,16.9)^{*}$ \\
\hline
\end{tabular}

*: Association.

associated with maternal near-miss. Maternal near-miss were 4.2 times more likely among women who were rural residents as compared to urban residents [AOR: $4.2,95 \% \mathrm{Cl}(1.3,13.9)]$. Likewise, study participants who were referred from other health facility were 5.5 more likely to had maternal near-miss as compared to who were not referred [AOR: $5.5,95 \% \mathrm{Cl}(1.8,17.4)]$. The odds of maternal near-miss were 10.2 times more likely among those who had a history of stillbirth as compared to those who didn't [AOR: $10.2,95 \% \mathrm{Cl}$ (1.4, 71.8)]. Pregnant women who reach $>60$ minutes to the hospital were 4.8 times more likely to develop maternal near-miss as compared to those who reached within 60 minutes [AOR: 4.8, 95\% Cl $(1.34,16.9)]$ (Table 4).

\section{Discussions}

In this study, The prevalence of maternal near-miss was $16.1 \%$ with $95 \% \mathrm{Cl}(12.5,20.3)$. This study was almost in line with finding from global reported $15 \%$ and SubSahara countries $12.2 \%$ respectively $[2,16]$. However, it is higher than the report in India at 1.6\%, Bangladesh $2 \%$, Brazil $0.5 \%$, Ghana 3\%, and Southwestern Nigeria at $1.8 \%[2,15,17-20]$. The current study is also higher than the study done in some parts of Ethiopia, Felege Hiwot
Hospitals 10.6\%, Addis Ababa Specialized Hospital $0.81 \%$, and Yirgalem hospitals $3.3 \%[10,21,22]$. The reason for the high prevalence might be related to the study area difference because in this study majority of the patients including outpatient, and inpatients are being referred from collateral health facilities to the hospital. The other reason might be since the data were collected prospectively, there were no missing cards or missing patients.

In another way, in this study the prevalence of maternal near-miss was lower when compared to the studies done in Amhara region hospital 23.3 and MizanTepi Hospital 24.85\% [23,24]. The possible reason might be the difference in a health facility and sociodemographic difference.

This study also revealed that almost half the underlying cause of maternal near-miss was due to hypertensive disorder of pregnancy and most maternal near-miss occurred before arrival to these hospitals. This study is similar tothe study done in India, Nigeria, Addis Ababa Specialized Hospital, and southern Ethiopia $[17,21,22,25]$. In the current study, the rural residence was one of the significantly associated factors for 
maternal near-miss. This study was in line with the study conducted in Nigeria, Ethiopia, Amahara regional state, Mizen-Tepi South region, Addis Ababa Specialized Hospital, and Jimma Specialized Hospital [21,24-27]. Because most of the near-miss cases were frequent and related to delays in reaching and receiving adequate care [28].

Similarly, being referred from other health facilities also was found as a significantly associated factor with maternal near misses. This is similar to study done in Ghana, South Africa, Gurage zone hospitals, and Addis Ababa Ethiopia $[19,21,29,30]$. Because most of the near-miss cases were frequent and related to delays in reaching and receiving adequate care. Another contributing factor for maternal near-miss in the study was a history of stillbirth. This finding was consistent with the study done in Bangladesh and Addis Ababa hospitals $[20,21]$. This might be women who had a history of the previous stillbirth in the previous pregnancy might have a chronic disease and obstetrics complications that might be complicated during pregnancy might have recurred in the current pregnancy. Second, maternal delay (time to reach the final care health facility) was found to have a significantly associated factor with a maternal near miss. This finding is in line with the study done in south Ethiopia, the Amhara region, the Tigray region, and Jimma [26,27,31,32] respectively.

\section{Conclusions}

In this study, the prevalence of maternal near-miss was relatively high. Being a rural residence, referred women, the time takes to reach the hospital, and the previous stillbirth were the factors independently associated with the occurrence of maternal near-miss. The presence of maternal near-miss in women is an independent risk factor for adverse perinatal outcomes. Strengthening the available health system in rural parts of the country with a focus on maternity service is also a crucial step to avert serious maternal complications. Hence, interventions rendered at the improvement in maternal health can lead to an improvement in perinatal outcomes.

\section{Consent for Publication}

Not applicable.

\section{Competing Interests}

The authors declare that they have no competing interests.

\section{Funding}

The authors received no specific funding for this work.

\section{Acknowledgment}

The authors thank all the study participants and data collectors.

\section{References}

1. Ashford L (2002) Hidden suffering: Disabilities from pregnancy and childbirth in less developed countries. Population Reference Bureau Washington, DC.

2. Tunçalp Ö, Hindin MJ, Souza J, Chou D, Say L (2012) The prevalence of maternal near-miss: A systematic review. BJOG 119: 653-661.

3. World Health Organization (2011) Evaluating the quality of care for severe pregnancy complications: The WHO nearmiss approach for maternal health.

4. Say L, Souza JP, Pattinson RC (2009) Maternal nearmiss-towards a standard tool for monitoring the quality of maternal health care. Best Practice \& Research Clinical Obstetrics \& Gynecology 23: 287-296.

5. Assembly G (2015) Transforming our world: The 2030 agenda for sustainable development. United Nations, New York, NY, USA.

6. World Health Organization (2014) Trends in maternal mortality: 1990 to 2013: Estimates by WHO, UNICEF, UNFPA, The World Bank and the United Nations Population Division.

7. Berg CJ, Callaghan WM, Syverson C, Henderson Z (2010) Pregnancy-related mortality in the United States, 1998 to 2005. Obstetrics \& Gynecology 116: 1302-1309.

8. Grobman WA, Bailit JL, Rice MM, Wapner RJ, Reddy UM, et al. (2014) Frequency of and factors associated with severe maternal morbidity. Obstetrics and Gynecology 123: 804-810.

9. Callaghan WM, Creanga AA, Kuklina EV (2012) Severe maternal morbidity among delivery and postpartum hospitalizations in the United States. Obstetrics \& Gynecology 120: 1029-1036.

10. Gebrehiwot Y, Tewolde BT (2014) Improving maternity care in Ethiopia through facility-based review of maternal deaths and near misses. International Journal of Gynecology \& Obstetrics 127: S29-S34.

11. Liyew EF, Yalew AW, Afework MF, Essén B (2017) Incidence and causes of maternal near-miss in selected hospitals of Addis Ababa, Ethiopia. PLoS One 12: e0179013.

12. Hogan MC, Foreman KJ, Naghavi M, Ahn SY, Wang M, et al. (2010) Maternal mortality for 181 countries, 1980-2008: A systematic analysis of progress towards Millennium Development Goal 5. The Lancet 375: 1609-1623.

13. Ababa A (2003) Federal democratic republic of Ethiopia ministry of health. Postnatal Care, Ethiopia.

14. Jabir M, Abdul-Salam I, Suheil DM, Al-Hilli W, AbulHassan S, et al. (2013) Maternal near miss and quality of maternal health care in Baghdad, Iraq. BMC Pregnancy and Childbirth 13: 1-9.

15. Galvão LPL, Alvim-Pereira F, de Mendonça CMM, Menezes FEF, do Nascimento Góis KA, et al. (2014) The prevalence of severe maternal morbidity and near-miss and associated factors in Sergipe, Northeast Brazil. BMC Pregnancy and Childbirth 14: 1-8.

16. Filippi V, Chou D, Ronsmans C, Graham W, Say L (2016) Levels and causes of maternal mortality and morbidity.

17. Gupta D, Nandi A, Noor N, Joshi T, Bhargava M (2018) Incidence of maternal near-miss and mortality cases in central India tertiary care center and evaluation of various causes. The New Indian Journal of OBGYN 4: 112-116. 
18. Say L, Pattinson RC, Gülmezoglu AM (2004) WHO systematic review of maternal morbidity and mortality: the prevalence of severe acute maternal morbidity (near-miss). Reproductive Health 1: 1-5.

19. Tunçalp Ö, Hindin MJ, Adu-Bonsaffoh K, Adanu RM (2013) Assessment of maternal near-miss and quality of care in a hospital-based study in Accra, Ghana. International Journal of Gynecology \& Obstetrics 123: 58-63.

20. Sikder SS, Labrique AB, Shamim AA, Ali H, Mehra S, et al. (2014) Risk factors for reported obstetric complications and near misses in rural northwest Bangladesh: analysis from a prospective cohort study. BMC Pregnancy and Childbirth 14: 347.

21. Firdawek E (2018) Maternal near miss: incidence, causes, factors and adverse perinatal outcomes in Addis Ababa, Ethiopia. BMC Pregnancy and Childbirth 18: 345.

22. Wakgar N, Dulla D, Daka D (2019) Maternal near misses and death in southern ethiopia: A retrospective study. Ethiopian Journal of Reproductive Health 11: 17-25.

23. Dile M, Abate T, Seyum T (2015) Proportion of maternal near misses and associated factors in referral hospitals of Amhara regional state, Northwest Ethiopia: An institutionbased cross-sectional study. Gynecol Obstet 5: 2161-0932.

24. Yemaneh $Y$, Tiruneh $F$ (2018) Proportion and associated factors of maternal near misses in selected public health institutions of Keffa, Bench-Maji and sheka zones of south nations nationalities and peoples regional state, South West Ethiopia, 2017. A Crossectional Study.

25. Aduloju OP, Aduloju T, Ipinnimo OM (2018) Profile of maternal near miss and determinant factors in a teaching hospital, Southwestern Nigeria. Int J Obstet Gynaecol Res 1: $598-617$.
26. Woldeyes WS, Asefa D, Muleta G (2018) Incidence and determinants of severe maternal outcome in Jimma University teaching hospital, South-West Ethiopia: A prospective cross-sectional study. BMC Pregnancy and Childbirth 18: 255.

27. Mekonnin AW, Mengesha EW, Dinku G (2019) Delay in the maternal near-miss case and associated factors among women admitted in Felege Hiwot comprehensive specialized hospital, northwest Ethiopia.

28. Fekadu M, Regassa N (2014) Skilled delivery care service utilization in Ethiopia: analysis of rural-urban differentials based on national demographic and health survey (DHS) data. African Health Sciences 14: 974-984.

29. Kasahun AW, Wako WG (2018) Predictors of maternal near-miss among women admitted in Gurage zone hospitals, South Ethiopia, 2017: A case-control study. BMC Pregnancy and Childbirth 18: 260.

30. Iwuh I, Fawcus S, Schoeman L (2018) Maternal near-miss audit in the Metro West maternity service, Cape Town, South Africa: A retrospective observational study. South African Medical Journal 108: 171-175.

31. Mekango DE, Alemayehu M, Gebregergs GB, Medhanyie AA, Goba G (2017) Determinants of maternal near-miss among women in public hospital maternity wards in northern Ethiopia: A facility-based case-control study. PLoS One 12: e0183886.

32. Worke MD, Enyew HD, Dagnew MM (2019) The magnitude of maternal near misses and the role of delays in Ethiopia: A hospital-based cross-sectional study. BMC Research Notes 12: 585. 